\title{
Skate Transnacional: difusão de performance e técnicas corporais em vídeo-partes
}

\author{
Giovanni Cirino \\ Doutor em Antropologia \\ Professor na Universidade Estadual de Londrina, Brasil \\ cirinogiovanni@gmail.com
}

\begin{abstract}
Resumo: O presente texto tem a intenção de refletir sobre produções audiovisuais das marcas e atletas praticantes do skate tomando como questão central os desafios levados pelas diferentes técnicas para a execução de determinadas manobras. A partir do material audiovisual produzido por certas marcas e determinados atores, nossa reflexão procura acompanhar discursos sobre o aprendizado e possibilidades técnicas de realizações dadas pela particularidade dos processos de difusão das performances. Para tal foram conduzidas sessões de vídeos com skatistas experientes focando o interesse nas particularidades de circulação das técnicas e práticas corporais.
\end{abstract}

Palavras-chave: Skate; Video-parte; Comportamento Restaurado; Cultura Transnacional.

Abstract: This text intends to reflect on audiovisual productions of skateboarding brands and athletes taking as a central issue the challenges brought by different techniques to perform certain maneuvers. From the audiovisual material produced by certain brands and actors our reflection seeks to follow discourses on learning and technical possibilities of achievements given by the particularity of diffusion performance's processes. For this purpose, video sessions were conducted with experienced skaters focusing the interest in the particularities of circulation of body techniques and practices.

Key-words:Skateboarding; Video-part; Restored Behavior; Transnational Culture. 
É preciso ver técnicas e a obra da razão prática coletiva e individual, lá onde geralmente se vê apenas a alma e suas faculdades de repetição (MAUSS, 2003: 404).

\section{Skate no Brasil: um breve histórico}

A prática do skate no Brasil remonta o início da década de 1970 quando surgem os primeiros skatistas e as primeiras pistas. São Paulo como um dos lugares pioneiros no Brasil tornou-se referência, bem como outras cidades que começaram a juntar os primeiros praticantes. Na década de 1970 os equipamentos eram bastante escassos, diferentes e com limitações significativas em termos de qualidade e variedade. Foi somente no final da década de 1970 que os equipamentos importados começaram a chegar nas lojas. Até então somente quem tinha acesso a viagens conseguia um equipamento de qualidade para andar ${ }^{1}$.

Em 1974 foi realizado o primeiro campeonato de skate no Brasil. Foi no Primeiro Clube Federal, no Rio de Janeiro. Ainda nesse ano foi inaugurada o que seria provavelmente a primeira pista de skate do Brasil (e provavelmente da América Latina) na Praça Ricardo Xavier da Silveira, em Nova Iguaçú, também Rio de Janeiro. Logo em seguida, em fevereiro de 1977, foi inaugurada uma pista em São Paulo no condomínio residencial Alphaville e no mesmo ano surge a Wave Park localizada na Avenida Santo Amaro em São Paulo (ver documentário “Uretano no Asfalto" [2013]).

A partir do final dos anos 1970 a prática do esporte foi sendo ampliada de diversas maneiras, seja ganhando mais adeptos, seja com o surgimento das marcas, campeonatos, times, publicações e pistas. No ano de 1985 o Itaguará Country Club da cidade de Guaratinguetá realiza seu primeiro campeonato com a presença dos renomados skatistas americanos Dave Duncan e Tony Alva. Foi nesse campeonato que se deu a inauguração da Revista Overall e em março de 1986 chegava às bancas a Revista Yeah Skate. Também foi em 1986 que uma delegação brasileira participou do Campeonato Mundial no Canadá e em 89 em Münster na Alemanha, tendo como melhor colocação o $4^{\circ}$ lugar de Lincoln Dyo Ueda.

Em 1988 no Brasil realiza-se o Sea Club - Overall em São Paulo com a participação de Tony Hawk e Lance Mountain, ambos integrantes da chamada Bones Brigade equipe de skatistas patrocinados por uma das principais marcas norte-americanas naquele momento, a Powell Peralta. Também nesse mesmo ano aconteceu a $1^{\text {a }}$ Copa Itaú no Rio de Janeiro, com presenças importantes como Mark Gator, Joe Jhonson, Ken Park e Mike Alba. No final dos anos 1980 outros eventos significativos aconteceram no Brasil como, por exemplo, a vinda do skatista profissional Christian Hosoi, o circuito Alternativa Rock Skate que ocorreu em várias cidades do nordeste, entre elas Salvador e Recife.

Portanto, a década de 1980 marca o início de uma expansão da prática alavancando também uma indústria antes inexistente no Brasil. Companhias, praticantes, lojistas, lugares específicos. Tudo isso possibilitou um crescimento relativamente independente da indústria dos brinquedos à qual estavam ligadas as primeiras companhias que fabricavam materiais, equipamentos e acessórios para a prática. Roupas e tênis que antes eram adaptadas para a prática também começam a ser produzidos especificamente para o skate. A década de 1980 é marcada pelo surgimento de companhias que usavam as marcas norte americanas como referência. Muitos produtos eram lançados “à imagem e semelhança” das marcas estadunidenses.

1 Os termos, nomes de manobras, marcas, partes e peças do skate provenientes da língua inglesa não serão escritos em itálico pois serão tratados como "categorias nativas". Importante mencionar que são utilizados na língua original (inglês) não apenas no Brasil, mas em todos os países que praticam o esporte. 
O Campeonato Mundial de Münster de 1989 foi um marco para o skate brasileiro, pois possibilitou não apenas aos skatistas brasileiros estarem entre os melhores do mundo, mas também visibilizou o "problema" das companhias brasileiras que copiavam produtos das empresas estrangeiras (BRANDAO, 2011).

O início dos anos 1990 é marcado por um desaquecimento da "indústria do skate", não apenas pelas dificuldades dos próprios skatistas em acompanhar a evolução de outros praticantes ao redor do mundo, principalmente Estados Unidos, mas na Europa também. Países como Inglaterra e Espanha tornam-se centros importantes de difusão e evolução do skate fora da América do Norte. Paralelamente às dificuldades dos praticantes, o cenário econômico no Brasil era bastante instável para uma nascente indústria ligada a setores do lazer e entretenimento. A política econômica desempenhada pelo governo de Fernando Collor de Melo - sempre lembrada pela abertura do mercado nacional para produtos importados e pelo confisco das poupanças anunciado em 1990 pela então ministra Zélia Cardoso de Melo em cadeia nacional termina por enterrar quase de forma completa a então recém-nascida indústria brasileira do skate.

Menos do que remontar a história do skate no Brasil, este breve e resumido histórico acima apresentado tem o objetivo de referenciar, minimamente, de que forma o skate (prática e marcas) ganham e perdem espaço no contexto de um país cuja prática era quase inexistente. Durante a década de 1990 tudo se passava como se as marcas estrangeiras fossem as únicas referências possíveis para o skate nacional. Foi somente no final da segunda metade dos anos 1990 que o mercado volta a se aquecer e possibilitar novamente a produção de eventos, equipes patrocinadas, contratação dos chamados gerentes de equipe (os team managers) e a retomada de competições locais, regionais e nacionais com ranking de atletas e salários "profissionais" (BRANDAO, 2011; 2010; 2009; MACHADO, 2011).

No final dos anos 1990 e início dos anos 2000 um novo cenário se desenha com marcas fortes como a Drop Dead, a Qix e a Crail. Começa-se a ser utilizado com mais frequência o termo "atleta" para os praticantes profissionalizados e amadores, os campeonatos são retomados e uma nova geração de skatistas passa a protagonizar o cenário. Muitos skatistas passam a viajar para os países estrangeiros onde o skate tem mais tradição como, por exemplo, os Estados Unidos, e se tornam também patrocinados por marcas importantes integrando as novas equipes. Esse é o caso de Bob Burnquist, Lincoln Ueda, Rodrigo TX e Alex Carolino, entre outros, que figuram em importantes equipes e vídeos de suas marcas patrocinadoras.

Nos anos 1990 as marcas americanas se multiplicam e ampliam seu mercado. Para se ter uma ideia, funda-se em 1995 a International Association of Skateboard Companies (IASC) reunindo diversas marcas ligadas à produção de materiais, manufaturados, distribuidores, organizadores de eventos, proprietários de skateparks particulares e indivíduos [https:/ / theiasc.org].

Os chamados "vídeos de skate" existem desde a primeira metade dos anos 1980, no entanto, apenas algumas marcas realizavam esse tipo de produção. Porém, após a década de 1990 multiplicam-se também as empresas que percebem o papel importante dos vídeos como peças publicitárias. A princípio apenas algumas marcas conseguiam investir nesse tipo de produção como o caso das gigantes Powell Peralta e Santa Cruz. Ao mesmo tempo que se multiplicam as companhias, também aumentam o número de skatistas patrocinados profissionalizados, dos eventos e das produções audiovisuais, surge um novo "ator" nesse cenário: o vídeo-maker, ou apenas maker.

Para além dos vídeos pensados e produzidos pelas marcas, surgem também os chamados "vídeos magazines", revistas em formato áudio-visual dando outro suporte a algo que já existia que eram as revistas impressas, muitas das quais passam a ganhar a versão "vídeo" para suas edições mensais, como o caso da Thrasher Magazine. 
Exemplos de vídeo-magazines são a "411" e a “On" que tiveram duração considerável e mercado internacional para a visibilidade dos skatistas. Paralelamente às competições, o trabalho com os vídeos tornou-se cada vez mais profissionalizado. Nessa área surgem profissionais específicos e os skatistas que, a despeito das competições, trabalham quase exclusivamente para os vídeos, como o caso do skatista expoente Daewon Song (GIAMARINO, 2017; OLIC, 2010).

Nesse sentido, o presente artigo pretende colocar em questão a circulação das técnicas corporais a partir das produções audiovisuais. Mais especificamente pretende-se, a partir de alguns exemplos, demonstrar o quanto os vídeos são fundamentais para a difusão das técnicas e em última análise, como são importantes para a ampliação do nível do skate no Brasil em diversas modalidades, como vem sendo demonstrado com os resultados de diversas competições de alto nível em diferentes modalidades, mas notadamente nas modalidades street, vertical e park ${ }^{2}$.

\section{As "vídeos-partes" como campo de atuação e produção}

Diversas são as iniciativas para produzir materiais audiovisuais no meio do skate. Existem as produções mais tradicionais, que remontam os anos 1980 quando uma marca produzia um "filme" no qual toda a sua equipe, principalmente os "profissionais", aparecia representada. Os skatistas apareciam tanto individualmente - ou seja, uma sequência de manobras realizadas pelo mesmo sujeito - quanto em sessões. Sessão, session é o nome atribuído ao período em que se está praticando, seja sozinho ou em companhia de outros skatistas. Nesse caso são partes nas quais skatistas aparecem alternando suas manobras. Essas produções tiveram grande penetração no Brasil a partir de marcas como a Santa Cruz, a Powell Peralta e a Alva. Todas marcas norte-americanas protagonizadas por skatistas mundialmente conhecidos como Tony Hawk, Christian Hosoi, Tony Alva, Mike McGill, Steve Caballero, Lance Mountain, Tommy Guerreiro, Jeff Grosso, Natas Kaupas, Rodney Mullen, entre muitos outros.

Além dessas produções tradicionais, foram sendo realizadas produções com outros formatos, como o caso das chamadas "vídeo-magazines", que são as herdeiras das revistas (como a já mencionada Thrasher, e outras como a PowerEdge e Transworld), os documentários (enfocando um época, um local, uma marca ou equipe, ou até mesmo um skatista específico), os "road movies" com equipes fazendo turnê por diversas cidades e/ou países. Com o passar dos anos as produções foram se diversificando, profissionalizando e ganhando outros caráteres. Se antes o audiovisual era basicamente usado para divulgação da empresa, com os novos formatos a produção audiovisual ganha um caráter mais focado nos skatistas. Nesse sentido, grandes campeões como Paul Rodrigues, Eric Koston e Nyjah Houston lançam vídeo-partes extremamente aguardadas, comentadas, apreciadas, compartilhadas, etc.

2 Entre as principais modalidades praticadas estão o downhill, freestyle, o street, o vertical, o park e a megarampa. Para definir minimamente cada uma delas, pode-se dizer que o downhill é a modalidade praticada em ladeiras, em alta velocidade executando manobras (ou não) ao longo da descida, freestyle é marcado pelas manobras de solo sendo, portanto, praticado apenas no solo, plano, sem obstáculos. Já o street, como o nome sugere, refere-se à prática do skate pelas ruas da cidade utilizado como obstáculos a própria cidade e suas construções como, por exemplo, calçadas e guias, escadas, corrimãos, paredes, etc. O vertical é o skate praticado numa pista própria chamada de Half-pipe, que é uma pista em forma de "U" com aproximadamente 4 metros de altura na qual o skatista utiliza principalmente para aéreos e manobras na borda. O park é a modalidade praticada também em uma pista, porém no formato "bowl". Esta modalidade surge a partir do uso das piscinas vazias que eram utilizadas simulando as paredes de uma onda do mar utilizadas pelos surfistas. Diferente do Brasil, as piscinas na América do Norte possuem as paredes arredondadas para evitar o congelamento da água. E recentemente foi criada mais uma modalidade chamada de megarampa que consiste em um aclive íngreme de aproximadamente 30 metros de altura que projeta o skatista em uma rampa. Após essa primeira rampa há um vão e a aterrisagem se dá em outra parte da rampa onde se tem um "quarter" que é um dos lados do Half-pipe, porém com aproximadamente de 8 a 10 metros de altura. 
A internet obviamente possui um papel fundamental para a divulgação e circulação das produções. Seja com sites específicos como o <www.skatevideosite.com $>$ ou <www.skateboarding.transworld.net> que são sites dedicados a serem repositórios de produções. Mas também os canais de produtores e/ou marcas no site Youtube dedicados especificamente a essas produções. São os casos, por exemplo, da Thrasher, The Creature, Berics, Transworld, Bronson, entre outros.

A internet mudou totalmente a forma como os vídeos de skate são pensados, realizados e divulgados. Atualmente as marcas não ganham dinheiro diretamente através da venda de cópias dos filmes como ocorria nos anos 1990 e 2000. As produções são divulgadas e difundidas a partir, principalmente, mas não só, do site Youtube. Nesse site também são divulgadas produções realizadas a partir da transmissão ao vivo de eventos, competições e festas do skate. Percebe-se, portanto, que a diversificação dos tipos de produções acarretou diversas alterações nas formas que os "vídeos de skate" são consumidos pelo mundo afora. Nos últimos 30 anos, o esporte também passou a ser praticado em diversos lugares no planeta, como os países nórdicos, do oriente médio e do oriente propriamente dito (GIAMARINO, 2017).

Certamente, a internet tem um papel importante na difusão do esporte pelo mundo. Da mesma maneira que o site Youtube atualmente centraliza a divulgação das produções, outro aplicativo de celular também potencializa a publicização e visibilidade das edições: trata-se do Instagram. Como o aplicativo é utilizado por marcas e skatistas, a publicidade das peças se dão de diferentes formas, sendo inclusive replicadas como repostagens em diversos locais, como contas de marcas, lojas, revistas e outros skatistas. Nesse aplicativo, além das postagens realizadas pelo proprietário de uma conta (no feed), também são realizadas através dos stories, que são publicações mais efêmeras (duram apenas 24 horas) porém amplificam e multiplicam as visualizações das postagens. No aplicativo é possível perceber que certas filmagens (principalmente aquelas que mostram manobras difíceis, nunca realizadas, criativas, radicais em altura ou grau de dificuldade, são replicadas praticamente à exaustão. Um exemplo disso foi a recente manobra realizada pelo skatista Mitchie Brusco no X Games de 2019 na modalidade Mega Rampa com o $1260^{\circ}$, um aéreo girando três voltas e meia, nunca antes realizado.

A diversidade de produções importa em nossa discussão para salientar o papel que atualmente as filmagens têm no universo da prática do skate. Porém mais do que revelar uma ampliação do uso do recurso para o universo dos negócios, as produções têm sido deveras utilizadas para o alargamento do universo de aprendizado. Portanto, estou me referindo não apenas à divulgação de novas manobras, novos produtos de marcas, eventos, campeonatos, apresentações, demonstrações, shows e outros. Estou me referindo ao uso do audiovisual para a difusão de técnicas e o aprendizado de manobras.

\section{Vídeo-partes e transmissão de conhecimento}

O uso do vídeo esteve presente no skate desde muito cedo na história do esporte. Aqui no Brasil, a despeito das inúmeras diferenças em relação ao mercado quando comparado a países da Europa ou América do Norte, não foi diferente. Inicialmente o principal uso do vídeo pelos praticantes estava relacionado com aprendizado e inspiração. Foi nas telas de filmes como o Back to the Future ("De volta para o futuro") (1985) ou Police Academy ("Loucademia de Polícia") (1984) que muitos skatistas viram pela primeira vez o skate ${ }^{3}$.

Os vídeos que tinham o skate como protagonista foram determinantes para a função que os vídeos passaram a ter posteriormente. Como afirma Lance Mountain ao se referir aos vídeos e sua relação com a prática do skate no Brasil:

3 Sobre algumas das principais ideias presentes nesta seção, agradeço a interlocução de Fabio Hirata, Joilton Ribeiro e Rafael Ramos, os quais estão obviamente escusados de quais equívocos presentes neste texto. 
No começo do anos 90 com a chegada dos vídeos, os garotos brasileiros nos viam nos vídeos e pensavam 'é assim que a gente tem que andar' e então eles tentavam andar como a gente andava nos vídeos e 'a gente tem que ir pra lá', então eles vieram pra cá e viram que os americanos não andavam de skate como nos vídeos, ao vivo. E eles pegaram aquilo e criaram uma nova realidade (Grifos nossos. Vida sobre rodas [DANIEL BACCARO, 2013]).

Esta fala dá uma noção da importância que os vídeos tiveram para que os skatistas brasileiros alcançassem o nível que alcançaram, colocando o Brasil no mapa do skate mundial. Essa "nova realidade" começou a ser gestada num momento de grande recessão econômica no Brasil em que a maioria das empresas ligadas ao skate no Brasil fecharam suas portas. No documentário Dirty Money - A geração do Skate, (2013) que relata o contexto de produção de um importante vídeo no início dos anos 1990, o skatista profissional Alexandre Vianna também tece comentários sobre essa fase do skate no Brasil salientando a improvisação e precariedade:

A gente começou a receber [os vídeos], porque alguém tinha vindo dos Estados Unidos com vídeo novo (...) e aí todo mundo se juntava na casa de quem tinha o vídeo pra assistir e dava muita vontade de andar de skate" (Vida sobre rodas [DANIEL BACCARO, 2013]).

No entanto, o uso do vídeo também foi apropriado pelos brasileiros. De expectadores a produtores. Não demorou para que as filmadoras caseiras (as "handy cams") fosses apropriadas para serem utilizadas na filmagem de manobras e não apenas reuniões familiares. Outro skatista profissional Fabio Cristiano comenta o início da produção do documentário Dirty Money (2013):

[...] a gente imbicou de vez nesse negócio de andar de skate e fazer vídeo e dane-se, agora a gente não quer saber de patrocínio, campeonato, viagem, a gente que saber de fazer vídeo, aprender manobra, filmar e fazer vídeo. Vamos fazer isso, beleza! A gente começou a fazer isso e a gente começou a ir pra outro nível do skate, começou progresso, progresso, progresso" (Grifos nossos. Vida sobre rodas [DANIEL BACCARO, 2013]).

Os comentários de Lance Mountain, Alexandre Vianna e Fábio Cristiano nos dão uma ideia sobre a maneira que o vídeo (seja apenas assistindo ou produzindo) serviu e serve como catalizador da transmissão de conhecimentos técnicos, do aprendizado e da evolução. A "nova realidade" foi imaginada e concretizada a partir dos vídeos.

É muito comum observarmos os skatistas pedindo dicas uns aos outros sobre a realização de determinada manobra. Questões sobre como posicionar o corpo, tórax, ombros, como posicionar os pés no skate, como e onde pressionar o skate no momento da manobra. Quando se está na sessão com um outro praticante que consegue realizar determinada manobra que se quer aprender, perguntar é o caminho que parece ser o mais obvio. Porém, nem sempre é o caso.

Os vídeos são uma fonte bastante importante, por vários motivos. Não se trata apenas de aprender certa manobra. Mas realiza-la da melhor maneira possível. A mesma manobra pode ser realizada de várias maneiras. Não se trata apenas de realizar uma manobra, além da realização existem outros atributos de uma manobra que são de extrema importância para os praticantes como, por exemplo, a amplitude, altura, distância, estilo, contorção, entre outros aspectos.

Pedir dicas para aprender ou melhorar uma manobra que já se sabe é bastante presente, no entanto é frequente que os praticantes próximos também não saibam, ou também estejam em busca de aperfeiçoamento. É nesse sentido que os vídeos cumprem um papel importante. O skate, como muitas outras modalidades perfomativas, é uma prática que depende totalmente da habilidade, treino e criatividade do praticante. Além da difusão da simples informação que determinado movimento ou manobra é possível, os vídeos (e o Instagram atualmente também é fundamental para isso) mostram "como" determinada manobra foi realizada. 
Obviamente certos detalhes não são passíveis de serem apreendidos através da assistência de um vídeo como, por exemplo, qual a força que o pé pressionou a madeira do skate (o deck, aqui no Brasil usa-se muito o termo "shape" para se referir à madeira), ou então a direção do movimento, a pressão ou o direcionamento do movimento.

Porém muitas coisas podem ser aprendidas com o vídeo. É o caso do posicionamento dos pés, formas de realizar o giro, posição dos ombros, velocidade do movimento ou do giro, amplitude, altura, etc. Um recurso bastante usado nos vídeos é a câmera lenta. Tal recurso tornase fundamental, não apenas para conferir novamente a manobra. Para os skatistas que assistem, os detalhes "técnicos" (como posição do corpo, dos pés, velocidade do giro, tempo e altura da manobra) são detalhes aos quais se despende especial atenção.

É sobre esses detalhes que este texto procura se debruçar. Nos vídeos que são postados na Internet, através das várias plataformas possíveis, os skatistas do mundo inteiro reconhecem um âmbito extremamente significativo. Sempre que um vídeo novo sai, seja uma parte avulsa ou um vídeo completo de uma marca, o que chama mais a atenção são as manobras. Claro que a filmagem, a edição, a trilha sonora, o ritmo, a estética geral do filme, tudo é objeto de apreciação, mas as manobras são o foco, o essencial. A motivação é o desafio criado a partir de uma possibilidade dada.

Quando uma "nova" manobra é criada, imediatamente após sua divulgação arquiteta-se na cabeça de vários praticantes a vontade e, por que não, a necessidade de realiza-la. Cada sujeito avalia a partir de suas próprias habilidades a possibilidade (ou não) de realizar tal manobra. Não apenas a manobra em si, mas também o local é considerado. O aprendizado pode ser marcado por fases, tentativas, uma escalada em níveis de dificuldade ou altura e amplitude da manobra. Seja como for, tudo se passa como se a possibilidade dada pela realização de uma manobra feita por um skatista se espraiasse até que tal manobra se torna uma realidade para outros praticantes. A partir daí, a manobra se apresenta não mais como algo apenas imaginado, mas feito, objetivado. Não é à toa que em muitos vídeos os praticantes falam sobre a imaginação. "Você precisa imaginar antes, precisa 'ver' o movimento, se você se ver fazendo a manobra, você consegue". Essa fala resume bem o tipo de afirmação que me refiro.

Tomando como questão central os desafios levados pelas diferentes técnicas para a execução de determinadas manobras, os vídeos são parte essencial para a produção desse espraiamento. As produções recentes realizadas (ou divulgadas) por plataformas como Thrasher ou The Berrics são fundamentais. Interessante pensar a partir de alguns materiais em específico para termos mais alguns elementos.

Embora o exercício possa ser feito com diversos vídeos, inclusive tomando em consideração skatistas icônicos como Rodney Mullen ou Daewon Song, será considerado para efeito heurístico o skatista David Gravette. Trata-se de um skatista profissional de Issaquah, cidade norte americana do estado de Washington, patrocinado por marcas como Creature, Independent, Bones Wheels, Circa, Bronson Bearings. Recentemente foi lançado dois vídeos com participações desse profissional. Um intitulado "Creature - The Vídeo" (2018) e o outro intitulado apenas "Bronson" (2019) em referência à marca homônima que produz rolamentos. Ambos são importantes e significativos para o que se apresentará aqui. Em conjunto com tais produções, poucas semanas após a veiculação desses vídeos, são veiculadas também as partes chamadas de "rough cut", ou seja, são as filmagens das manobras com todas as tentativas, sem edição e sem a trilha sonora. Com tais materiais é possível avaliar melhor o grau de dificuldade para executar cada manobra. Os comentários dizem respeito, portanto, a esses dois vídeos com seus respectivos rough cut. 
São esses dois vídeos que serão considerados pois foram lançados recentemente e foram utilizados para conduzir sessões de conversas sobre técnica e vídeo com skatistas. Para além da criatividade em pensar as linhas e manobras a serem filmadas, as filmagens revelam aspectos que são notados como significativos para os skatistas. O que se pode perceber de forma bastante evidente é que os comentários são referentes à realização da manobra, ou seja, os skatistas se colocam no lugar daquele que aparece nas imagens.

[...] se você prestar atenção, ele vem no gás, no vídeo não parece mas ele tá no galeto. Mandar essa trick nesse gás é outro nível, cabreiro demais! Eu mando flipando desse jeito mas não nesse gás. E outra, o chão é punk, não é liso, não. Ele ta usando roda grande inclusive.

Eis o comentário de um dos meus interlocutores ao ver no vídeo o skatista profissional pulando uma escadaria de rua executando um ollie flip. Os comentários que chamam atenção para o nível de dificuldade: "isso é absurdo", "impossível”, "cabreiro", " bizarro", etc.

Para se ter uma ideia do nível de dificuldade das manobras realizadas em posição trocada, o "switch stance", pode-se usar como exemplo a realização de um trabalho manual por um sujeito destro. Um artista plástico, por exemplo, ao realizar um desenho ou uma pintura, um monge budista produzindo um kanji, ou então um relojoeiro montando um pequeno mecanismo. Para além da dificuldade de realização da atividade em si, pode-se imaginar agora esses sujeitos realizando as mesmas atividades com a mão esquerda, sendo destro ${ }^{4}$.

Um outro exemplo de manobra talvez possa ilustrar. Trata-se de nollie hell flip krooket descendo um corrimão redondo de uma escada de 9 degraus. Não se trata de um corrimão pequeno, mas também não é dos maiores, no entanto, ao assistir essa manobra tece-se o seguinte comentário:

[...]o pé de trás [que é o pé que chuta o heel flip] dele é totalmente diferente. [Levantou-se do sofá e mostrou como posiciona seu pé para essa manobra]. O jeito mais fácil é colocando o pé da frente cheio e o pé de trás mais inclinado e não tão paralelo, fazer igual ao Koston, sabe? Mas do jeito que eu to vendo aí é mais difícil ainda.

Há grande chance de cada skatista realizar a mesma manobra posicionando os pés de maneira particular é a ainda acertar a manobra. Porém são os profissionais (em suas apresentações e, claro, nos vídeos-partes) que mostram como fazer tendo o melhor aproveitamento em termos de facilidade, extensão, altura e estilo dessa mesma manobra.

\footnotetext{
4 Para se ter uma noção de como as manobras são constituídas, alguns termos são necessários. O skatista pode se posicionar de duas formas sobre o skate: com o pé esquerdo na frente [posição chamada de "regular"], ou então com o pé direito na frente [posição chamada "goofy"]. Os movimentos e suas variações se dão a partir das maneiras possíveis de posicionar o corpo em relação ao skate, ao movimento e ao obstáculo. Os termos utilizados para essas referências são (para quem anda com o pé direito na frente, por exemplo [goofy]: Front side [quando o skatista realiza a manobra de frente para a transição ou o obstáculo]; Back side [quando o skatista realiza a manobra de costas para a transição ou o obstáculo]; Na base [andar pra frente com o pé direito na frente]; Switch stance [ss, andar pra frente com a base trocada]; Ollie Air [tirar o skate do chão batendo o tail, que é a parte de trás no chão]; Nollie [batendo o nose, que é a parte da frente]; Kick Flip [chutando o giro com a ponta do pé da frente]; Heel Flip [chutando o giro com o calcanhar do pé da frente]; Forward [pra frente]; Fakie [pra trás]; Varial [girando o skate $180^{\circ}$ no sentido anti-horário]; Shovit [girando o skate $180^{\circ}$ no sentido horário]; Slide [deslizando com a madeira ou seja com o shape, que pode ser com a parte central entre os eixos (rock slide), com a parte da frente (nose slide) ou com a parte de trás (tail slide)]; Grind [deslizando com os eixos, que pode ser com ambos [fifity fifity, 50/50, apenas com o de trás (stand up grind), ou apenas o da frente (nose grind)]; Manual [andar equilibrando apenas com o eixo de trás]; Nose manual [andar equilibrando apenas com o eixo da frente]; Nose Willie [andar de fakie equilibrando apenas com o eixo de trás]; Switch Manual [andar pra frente com a base trocada apenas com o eixo de trás].
} 
Em outros casos, conta a criatividade do skatista. A percepção da cidade (e dos obstáculos) se dá de maneira específica de acordo com a habilidade. Ou seja, para um lugar que um skatista não percebe a possibilidade de execução, outro pode "ver" já determinada manobra. Ou seja, o nível de habilidade e criatividade de cada skatista determina a maneira que a cidade é percebida (MACHADO, 2011). A forma que se constrói uma manobra se dá a partir da interação que o skatista realiza colocando em agência sua habilidade frente ao novo obstáculo.

Embora se possa notar recorrências obvias a partir de um nível de habilidade básico, essa interação é ou pode ser absolutamente original e particular.

O combo: fontside tail slide; backside rock slide no corrimão; fs 180 switch grind na borda do segundo lance de escada. Essa sequência realizada numa escada curta, com pouco espaço para entrada e pouco tempo para arrumar os pés entre uma manobra e outra torna a proposta bastante difícil. Como podemos ver no "rough cut" (BRONSON, 2019) [9' 02"] foram necessárias 19 tentativas até que se finalizasse a manobra a contento. É possível ver o grau de nervosismo, o inconformismo com o erro, a dificuldade em aceitar as particularidades do local e, finalmente, fazer a manobra de maneira satisfatória. Quando se fala dos combos, todas as manobras arroladas na sequência precisam estar encaixadas de maneira a contentar o skatista. Nos comentários de certas manobras (ou combos), as considerações sobre a velocidade, o posicionamento dos pés, a maneira de realizar o giro a partir dos braços e ombros, são detalhes tomados como fundamentais para se "acertar" a manobra.

[...] cê acha, não dá pra entender como ele faz. Não tem espaço pra entrar, não tem espaço entre o tailslide e o rock, ele precisa fazer com o pé do jeito que cai, não dá tempo de arrumar o pé pra mandar o rock, então precisa ser rápido e certo, sem erro.

Percebe-se nessas falas que os skatistas estão atentos a diversos aspectos técnicos no que tange ao grau de dificuldade. Sabe-se que numa vídeo-parte o skatista não executa qualquer manobra. Então as manobras selecionadas para entrar na edição final são sempre tratadas de uma maneira especial.

"Voltar" uma manobra significa concluir de forma a manter-se sobre o skate para dar continuidade à linha. A "linha" é a sequência completa de todas as manobras (ou combos) pensadas dentro de um determinado período de tempo ou espaço. As manobras do skate são construídas a partir de movimentos que vão se somando e/ou sobrepondo. Os movimentos quando encadeados podem produzir as manobras, combos (em geral pensados a partir de fases da manobra, como sequencias ou sobreposições) ou linhas (sequencias com diversas manobras ou combos). Por exemplo, no caso de manobras que deslizam, como os slides (deslizar com a madeira [shape ou deck] no obstáculo) e grinds (deslizar com os eixos no obstáculo), sempre se pensa em três momentos: 1) a entrada; 2) a maneira que o deslize ocorre e 3) a saída. Em cada momento há uma dificuldade envolvida.

Dado nível de dificuldade que o skate contemporâneo alcançou, os erros podem envolver muita dor e sofrimento. Gravette é um skatista que possui fama de acidentes dolorosos. Não é atoa que na descrição do vídeo lê-se: "É Gravette, então você sabe que há uma dose saudável de dor masoquista envolvida no Rough Cut. Às vezes você tem que enfrentar as chamas para atirar nos portões perolados ...". 


\section{Comportamento restaurado e técnicas corporais}

Segundo o antropólogo francês Marcel Mauss em sua famosa comunicação à Sociedade de Psicologia em 1934 (publicada posteriormente no Journal de Psychologie em 1935) intitulada "As técnicas do corpo", existem muitas formas de pensar as técnicas para o uso do corpo, seja em termos classificatórios ou a partir da enumeração biográfica. Mauss defende a ideia de existir técnica na vigília ou no sono, na atividade ou no repouso, com a presença de instrumento ou apenas do corpo.

Pensando com Mauss as formas classificatórias das técnicas do corpo ao se considerar a prática do skate seria possível visualizar nas quatro categorias enunciadas uma especificidade. A classificação por sexo, idade, rendimento ou transmissão aparece na prática do skate, no entanto, neste texto nos interessa especificamente as técnicas ligadas à transmissão. Mauss discute a natureza da educação e do adestramento do corpo sugerindo a abertura de um "novo campo de estudos" que estaria interessado em "incontáveis detalhes inobervados" (MAUSS, 2003: 411). O problema relacionado à ambidestria e à dissimetria motora do corpo humano são tratados a partir da educação, do aprendizado e da transmissão das técnicas para o uso do corpo tanto por Marcel Mauss quanto R. Hertz (1980).

Ao falar sobre as técnicas da idade adulta, da atividade e do movimento, Mauss nos apresenta uma sequencia de itens, corrida, dança, salto, escalada, descida, nado, acrobacia, atletismo, entre outros, mostrando o quanto essas atividades são realizadas de maneiras específicas e de acordo com o lugar e a época em que ocorrem. De fato, o autor demonstra que sempre se está frente a "montagens fisio-psico-sociológicas de séries de atos" (MAUSS, 2003: 420). Mauss está interessado na maneira que o ser humano adapta o corpo ao seu uso a partir de determinadas tradições. As montagens podem ser encontradas na prática do skate a partir da manobra, do combo ou da linha completa.

Da mesma forma que Marcel Mauss, Richard Schechner (1988) também irá considerar as maneiras que os movimentos do corpo são aprendidos, compartilhados e transmitidos a partir de determinadas tradições. Atentar para os detalhes inobservados é essencial para Schechner pensar sua "teoria da performance". A ideia da performance como algo prático está presente em todos os sentidos atribuídos a essa palavra como, por exemplo, execução, desempenho, façanha, proeza, representação, função, espetáculo, atuação, desempenho. Realizar uma performance tem a ver com a ideia de "mostrar fazendo". As performances marcam identidades, remodulam e adornam o corpo.

Para Schechner as performances são "comportamentos restaurados", ou seja,

[...] ações físicas, verbais ou virtuais, que não são [feitas] pela primeira vez, que são comportamentos duas vezes experienciados, ações realizadas para as quais as pessoas treinam e ensaiam. Todas as atividades humanas são passíveis de serem estudadas enquanto performances uma vez que cada ação, seja a mais simples e secundária ou a mais complicada é feita de comportamentos duas vezes vivenciados (SCHECHNER, 2006:30).

Ao falar da performance nos esportes, Schechner salienta a antiga relação que havia desde a Grécia Antiga entre o ritual, arte, competição esportiva e entretenimento de massa. Atualmente "esportes pertencem tanto ao entretenimento ao vivo quanto aos meios de comunicação, e representam ao mesmo tempo competição, ritual, espetáculo e negócios" (SCHECHNER, 2006: 33).

O skate pode ser pensado a partir das ideias de Mauss e Schechner na medida em que se enquadra em todas as definições acima mencionadas. 
Os exemplos mencionados foram pinçados para mostrar como o vídeo possui um papel extremamente significativo para a transmissão das técnicas de realização das manobras. É a partir do aprendizado que o skatista irá reproduzir no fluxo de sua linha, e isto caracteriza uma série de atividades, entre elas os esportes.

Podemos falar não exatamente do oposto à reflexão - uma vez que esta se produz a cada tentativa de realização de uma manobra - mas o ensaio, as tentativas, são uma fase importante para se alcançar uma performance fluída (CSIKSZENTMIHALYI, [1975] 2000).

A apropriação das técnicas para a realização de manobras é produzida pela circulação transnacional da cultura do skate através dos vídeos. Tanto no que se refere ao aspecto solidário ou competitivo presente no skate, observa-se um modo específico de difusão de aspectos culturais (questões estéticas, costumes, valores, música, entre outras coisas) propiciados pelas apropriações criativas que os skatistas do mundo todo fazem das técnicas que são exibidas nos vídeos, como foi sugerido a partir dos vídeos de David Gravette.

Nesse sentido pode-se afirmar a importância do vídeo para o aprendizado ligado a pelo menos três aspectos. A divulgação de determinada vídeo-parte, do skatista, das manobras que aparecem ali. Esse aspecto é essencial para a discussão que se intencionou enfocar neste texto, notadamente as técnicas e apropriações criativas que delas se fazem. Um segundo aspecto é o ganho de legitimidade que se tem quando uma vídeo-parte é divulgada. Neste meio, uma boa parte do respeito que um skatista ganha é produzido pela divulgação via vídeo das manobras que realiza (ou realizou em determinada situação, como uma turnê ou um campeonato). E por fim, um terceiro aspecto está relacionado com o mundo corporativo ao qual o skate está intimamente ligado. Ou seja, o vídeo sendo usado como uma espécie de "peça publicitária" que mostra o talento dos skatistas patrocinados por determinada marca. Esse aspecto é fundamental uma vez que as vídeo-partes estão em geral ligadas a certas marcas que dão suporte à produção audiovisual.

No skate observa-se comportamento restaurado, apropriação criativa, técnica imaginada e aprendida. Os movimentos necessários para uma manobra bem realizada estão na mente e no corpo, dependem de destreza, prática e habilidade: todos aspectos de uma cultura transnacional que utiliza o suporte audiovisual para, entre muitas outras coisas, transmitir conhecimento.

Para além desses três principais aspectos, os vídeos são considerados entre os skatistas como uma maneira bastante eficaz de mostrar suas habilidades e capacidades. As apropriações criativas se encontram não apenas nas técnicas para realizar as manobras, mas também nas diversas formas de registro e documentação, isso pode ser muito bem notado ao observar a quantidade de modalidades de vídeos presentes no Youtube, mas também e talvez principalmente, no uso que os skatistas (e também as marcas) têm feito do aplicativo para telefones celulares Instagram. Mas isso já é objeto de outra reflexão.

\section{Referências Bibliográficas}

BRANDÃO, Leonardo. A Cidade e a tribo skatista: juventude, cotidiano e práticas corporais na história cultural. Dourados: Ed. UFGD, 2011.

Esportes de ac a o: notas para uma pesquisa acadêmica. In: Revista Brasileira de Cieências do Esporte. V.32, n.1, Porto Alegre-RS, Sept. 2010.

A Introdução dos esportes californianos no Brasil: apontamentos para o início de uma discussão. In: Fronteiras, Revista de História. V.11, n.19, p.327-348, jan. jun., 2009. 
CSIKSZENTMIHALYI, Mihaly. "Flow Patterns in Everyday Life" (Cap. 9) In: Beyond Boredom and Anxiety: Experiencing Flow in Work and Play". San Francisco: Jossey-Bass Publishers, [1975] 2000.p. $140-160$.

GIAMARINO, Christofer D. Spatial Ethno-geographies of 'sub-cultures'in Urban Space: Skateboarders, Appropriative Performance, and Spatial Exclusion in Los Angeles. Columbia University, 2017.

HERTZ, Robert. “A preeminência da mão direita: um estudo sobre a polaridade religiosa”. In: Religião e Sociedade. Rio de Janeiro: Tempo e Presença, No 06, pp. 99-128, 1980.

MACHADO, Giancarlo. De "carrinho" pela cidade: a prática do street skate em São Paulo. Dissertação de mestrado em antropologia social. Universidade de São Paulo, USP, 2011.

MAUSS, Marcel. "As técnicas do corpo". In: Sociologia e Antropologia. São Paulo: CosacNaify, 2003.

OLIC, Mauricio Bacic. Entre o liso e o estriado: skatistas na metrópole. Dissertação de Mestrado em Ciências Sociais, PUC-SP, 2010.

SCHECHNER, Richard. Performance Theory. New York \& London: Routledge, 1988.

SCHECHNER. Richard. “What is Performance?”. In: Performance Studies: an Introduction. New York \& London: Routledge, pp. 28-51, 2006.

\section{Referências Videográficas}

“Uretano sobre o asfalto” (Luis Fernando Silva, 2017)

“Dirty Money - A geração do Skate” Alexandre Vianna e Ricardo Koraicho 2013

“Vida sobre rodas" (Daniel Baccaro, 2013)

Bronson video - (Bronson Bearings, 2019)

Creature - The Video (Lee Charron; Daf Noah, 2018)

Rough Cut from Bronson Video - (Bronson, 2019)

\section{Referências webgráficas}

https://theiasc.org

www.skatevideosite.com

www.skateboarding.transworld.net

https://www.youtube.com/watch?v=89a2v4-D_Z0 (Creature - The Vídeo).

https:// www.youtube.com/watch?v=Q6QOB3NNSCk\&t=6s (David Gravette's Bronson Part). 